\title{
Regime Shift of Genome Size Crossing the Chasm of Eukaryogenesis
}

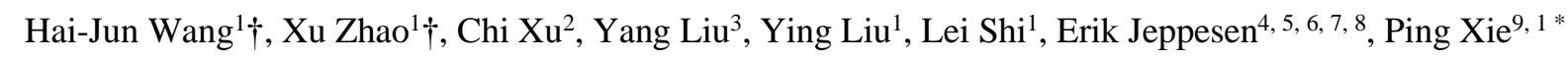

${ }^{1}$ Institute for Ecological Research and Pollution Control of Plateau Lakes, School of Ecology and

Environmental Science, Yunnan University; Kunming, China

${ }^{2}$ School of Life Sciences, Nanjing University; Nanjing, China

${ }^{3}$ Shenzhen Key Laboratory of Marine Microbiome Engineering, Institute for Advanced Study, Shenzhen University; Shenzhen, China

${ }^{4}$ Department of Bioscience, Aarhus University; Silkeborg, Denmark

${ }^{5}$ Sino-Danish Centre for Education and Research; Beijing, China

${ }^{6}$ Limnology Laboratory, Department of Biological Sciences, Middle East Technical University; Ankara, Turkey

${ }^{7}$ Centre for Ecosystem Research and Implementation (EKOSAM), Middle East Technical University; Ankara, Turkey

${ }^{8}$ Institute of Marine Sciences, Middle East Technical University; Mersin, Turkey

${ }^{9}$ Donghu Experimental Station of Lake Ecosystems, State Key Laboratory of Freshwater Ecology and Biotechnology, Institute of Hydrobiology, Chinese Academy of Sciences; Wuhan, China

$\dagger$ These authors contributed equally to this work.

* Corresponding author.

Email: wanghaijun@ynu.edu.cn; zhaoxu@mail.ynu.edu.cn; xuchi@nju.edu.cn; yangliu@szu.edu.cn; liuy35@hotmail.com; shilei1225@foxmail.com; ej@bios.au.dk; xieping@ihb.ac.cn

Abstract: The origin of the nucleus remains a great mystery in life science, although nearly two centuries have passed since the discovery of nuclei. To date, studies of eukaryogenesis have focused largely on micro-evolutionary explanations. Here, we examined macro-patterns of Cvalues (the total amount of DNA within the haploid chromosome set of an organism) for over 110,000 species and the chromosome numbers for over 11,000 species and their potential links with the state of atmospheric oxidation over geological time. Eukaryogenesis was in sync with an over 2.5 order-of-magnitude increase in genome size from prokaryote to eukaryote, and also with a rapid rise of atmospheric oxidation, suggesting that eukaryogenesis would have resulted from a regime shift of genomes driven by the oxidation-driven complexification and structuralization (e.g. chromatin packing).

Keywords: eukaryogenesis; genome complexification; atmospheric oxidation; macroevolution 


\section{Introduction}

Eukaryogenesis - the entire process by which the defining traits of eukaryotic cells arose in the lineage that eventually gave rise to all present-day eukaryotes - has long been of great interest to evolutionary biologists ${ }^{1,2}$, with multiple hypotheses proposed to date (e.g., various symbiotic models and the autogenous and exomembrane hypotheses) (table S1) ${ }^{3,4}$. Undoubtedly, eukaryogenesis should be a product of both macro- and micro-evolutions adapting to the changing environments. Although almost certainly related to origination of the nucleus in some way, it is not clear how to evaluate the relation between evolutionary complexification (increase in size) of genomes and eukaryogenesis. The acquisition of mitochondria capable of producing adenosine triphosphate (ATP) through oxidative phosphorylation has been proposed as prerequisite to eukaryogenesis ${ }^{5-7}$. However, little is known about the possible link between genome complexification and atmospheric oxidation (with high energy efficiency), and its potential role in eukaryogenesis. Since this study focused mainly on genomic evolution from prokaryotes to eukaryotes, a relatively simple typology of five biological kingdoms was applied, although more sophisticated typologies do exist.

In the present study, we have collected C-values for 110,431 species (covering bacteria, archaea, fungi, plants, and animals) (text S1) as well as chromosome number data for 11,792 species and explored their potential evolutionary relationships with the state of atmospheric oxidation over geological time. The term "C-value" refers to the amount (in picograms) of DNA contained within a haploid nucleus of an organism, being widely used to reflect the expected genetic complexity of a species, and in practice the term is often used interchangeably with genome size ${ }^{8}$. A chromosome is a complex linear organization of a DNA molecule aided by various packaging proteins (histones) and chaperone proteins. Each chromosome contains part of or all the genetic material of an organism. In a tiny cell, genomic complexification and structuralization were likely inseparable processes, which perhaps led to the emergence of eukaryotes upon reaching a threshold (Fig. 1). 


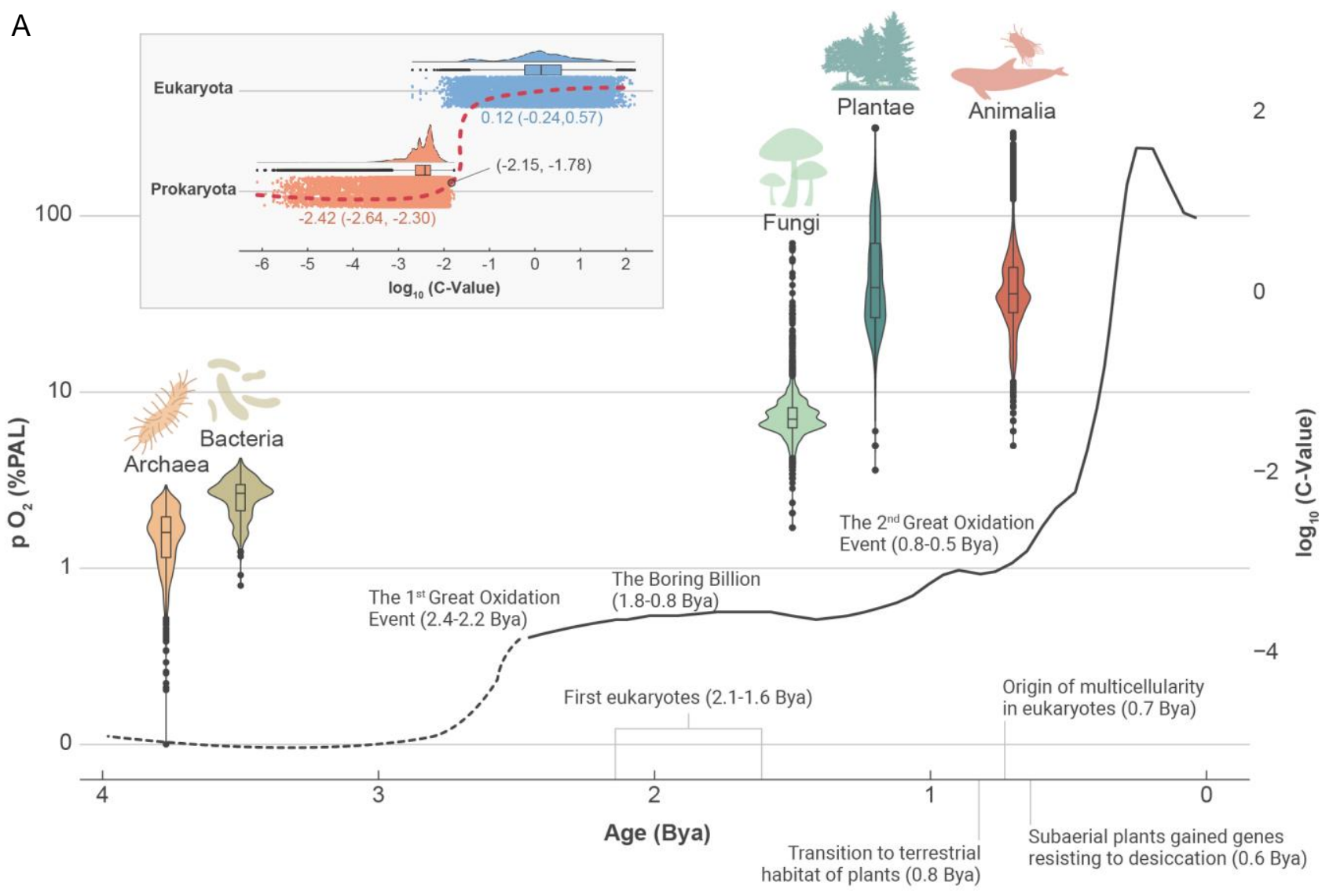

B

- Bacteria (Cyanobacteria), 2(1,15)

- Fungi, $2(1,12)$

- Plantae, $24(2,740)$

3

- Animalia, $34(6,138)$

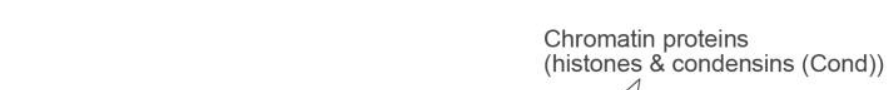

Chromosome/chromatin structure \& quantity

(histones \& condensins (Cond))

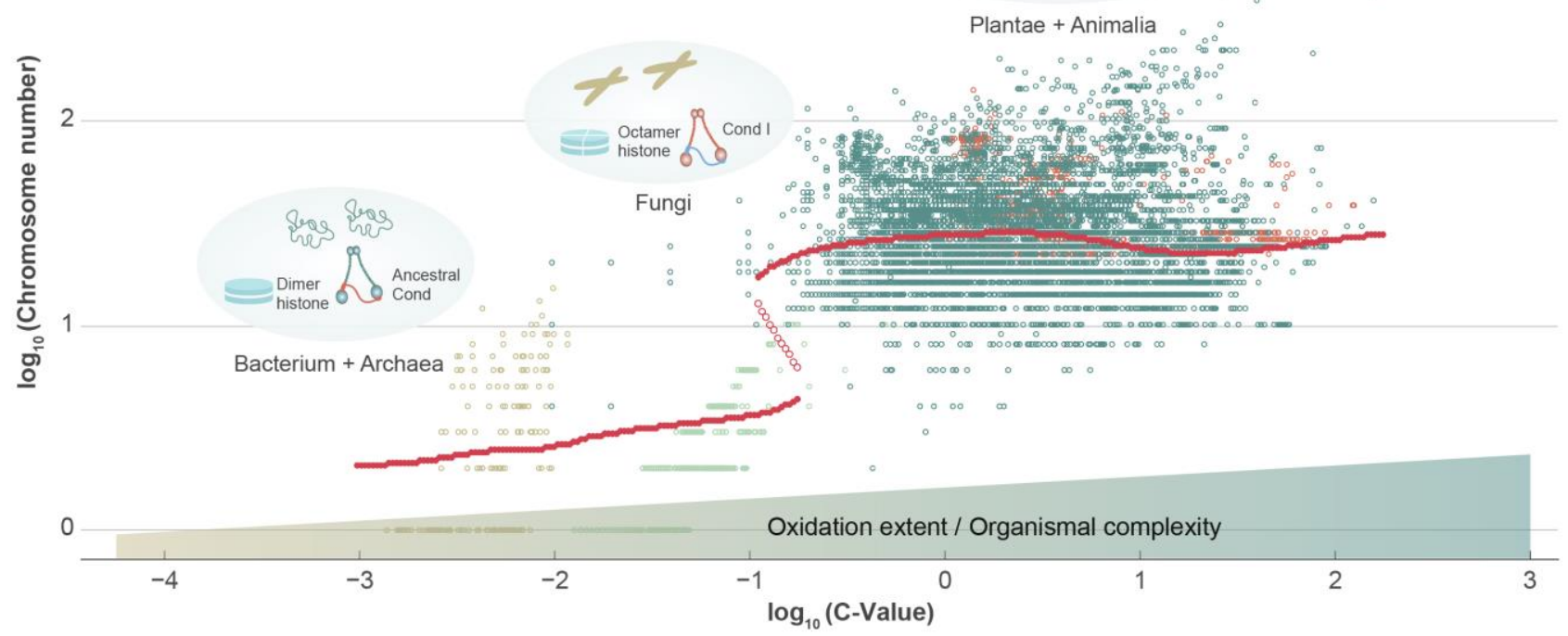


Fig. 1. Macro patterns of genome complexity (C-values) for the evolutionary lineages of various biological kingdoms. (A) C-value distributions of the kingdoms and percentage atmospheric oxygen concentration $\left(\mathrm{pO}^{2}\right)$ along with geological time. The first appearance time was estimated at ca. 3.77 Bya for archaea ${ }^{16}, 3.5$ Bya for cyanobacteria ${ }^{17}$, 1.5 Bya for fungi ${ }^{18}, 1.2$ Bya for plants ${ }^{19}$, and 0.7 Bya for animals ${ }^{20}$. The C-value distributions of prokaryotes and eukaryotes show their medians $\left(1^{\text {st }}\right.$ quartile, $3^{\text {rd }}$ quartile $)$, with blue open circle and value indicating the thresholds (95\%-100\%) for the transition from prokaryotes to eukaryotes. (B) Relationship of $\mathrm{C}$-value with chromosome number with fitting lines based on a potential landscape model. The data after the kingdoms shows the corresponding median (minimum, maximum) of the chromosome numbers. It should be noted that chromosomes for cyanobacteria are a kind of unstable circular form between chromatin and real chromosome ${ }^{21}$. The evolution of structure, quantity, and packing-associated proteins of chromosomes were also given along a gradient of organismal complexity and oxidation extent.

\section{Materials and Methods}

The approach of Potential Landscape Model (also termed as stability landscape) ${ }^{9}$ has been used to infer the existence of stable states across a given state space from noisy data ${ }^{10,11}$. This approach assumes an underlying stochastic system with a potential function:

$$
d z=-U^{\prime}(z) d t+\sigma d W
$$

where $z$ represents the focal state variable (here chromosome size), $U(z)$ represents the potential function, $\sigma$ represents the noise level, and $d W$ is a noise term. The equilibrium values were calculated by determining the local minima and maxima of the resulting potential landscape. In Fig 1B, the red curve (local minima of the potential landscape) represents the inferred stable equilibrium, and the open circles (local maxima of the potential landscape) represent unstable equilibrium.

Web sources for data of C-values and chromosome numbers are as follows. Bacteria and $\operatorname{archaea}^{12}$ : https://img.jgi.doe.gov/ ; Fungi ${ }^{13}$ : http://www.zbi.ee/fungal-genomesize/; Plants ${ }^{14}$ : https://cvalues.science.kew.org/ ; Animals ${ }^{15}$ : http://www.genomesize.com. 


\section{Results and discussion}

There has been a consensus that atmospheric oxidation had profound impacts on the evolution of life on Earth. Changes in the atmospheric oxygen level $\left(\mathrm{pO}_{2}\right)$ and the C-value distributions of the five kingdoms over geological time are presented in Fig. $1 \mathrm{~A}^{22-25}$. The median $\mathrm{C}$-value shows large differences between prokaryotes and eukaryotes, with the lowest being for archaea $\left(\log _{10}(\mathrm{C})=-2.76\right)$ and bacteria $(-2.41)$ (LC group), the intermediate for fungi $(-1.38)$ (MC group), and the highest for animals (0.16) and plants (0.23) (HC group) (Fig. 1A, table S2). According to the estimated first appearance time of each kingdom ${ }^{16-18,20,26,27}$, the LC group corresponds to the low $\mathrm{pO}_{2}$ period, the $\mathrm{MC}$ group to the moderate $\mathrm{pO}_{2}$ period, long after the First Great Oxidation Event (2.4 billion years ago, Bya), and the HC group to a period slightly before or during the Second Great Oxidation Event (0.8-0.5 Bya). The origination of life on Earth (3.85 Bya) and the appearance of the first eukaryote (2.1-1.6 Bya) shows at least a lag of 1.75 Bya ${ }^{28}$. However, the lag is only 0.3 Bya from fungus to plants ${ }^{18,19}$, and 0.5 Bya from plants to animals 19,20 , suggesting the potential role of atmospheric oxidation in promoting diversification and genome complexity, and thus speciation. Our view is supported by the idea that energy production by the acquisition of mitochondria could have enabled eukaryogenesis $5,6,29$.

Interestingly, the C-value distribution of prokaryotes (including bacteria and archaea) shows evidence of heavy crowding at the high-value end, while scattered at the low-value end and at both ends of the three eukaryotic kingdoms (Fig. 1A). This suggests an apparent barrier of upper C-values for prokaryotes, i.e., only if a C-value threshold was passed could a shift from prokaryote to eukaryote take place. If taking the highest 5\% value of this high-value end of prokaryotes, the $\mathrm{C}$-value threshold for the prokaryote-to-eukaryote shift can be defined as -2.15 $\sim-1.78\left(\log _{10} x\right)$.

The relationship between chromosome number and C-values showed a sigmoid shape (Fig. 1B). The test by a potential landscape model according to Livina et al. (2010) ${ }^{9}$ suggested two contrasting states, with fungi and bacteria (represented by cyanobacteria, the taxa with chromosome number reported) in the low-value group, while plants and animals in the highvalue group. This suggests that the transition from the lower to the higher group takes the shape of a regime shift. Additionally, the fact that eukaryotes have much larger genome sizes than prokaryotes suggests that accidental symbioses could not make a nucleus. In other words, the 
genomic complexity of eukaryotes could be greatly increased only if the evolution of the nucleus had experienced a long sequential process.

Related evolution of the structure (i.e., circular vs. linear), quantity (numbers), and packingassociated proteins of chromosomes along with the organismal complexity and oxidation extent was further summarized (Fig. 1B). The atmospheric oxidation likely promoted complexification and structuralization of genomes and hence triggered the origination of the nucleus after a sharp increase of genomic size upon crossing a threshold, as supported by the following facts or inferences. First, atmospheric oxidation provided the energetic basis for genomic complexification ${ }^{30,31}$. Second, there exists an upper limit of genomic size for prokaryotes. Third, formation of nuclear membranes and increase in chromosome number enabled orderly management and control of the complex biochemical system with increasing genomic complexity. Fourth, some proteins neofunctionalized to help highly efficient chromatin packing $^{32,33}$. Associated packing proteins are mainly simple nucleoid-associated ones in prokaryotes, whereas various complex ones (e.g., histones, cohesins, etc.) are present in eukaryotes $^{33,34}$. Eukaryotic chromosomes are therefore highly condensed and linked in an orderly manner to ensure that the genome fits inside the nucleus. For example, the chromosome packing ratio is as high as 10,000:1 for human beings when comparing the length of uncoiled DNA to that of a chromosome in metaphase (Annunziato, 2008); this ratio can be as high as 60,400 for some plant species ${ }^{35}$ and over 65,600 for fungi ${ }^{36}$ based on the length of chromosome and its genome contents ${ }^{35}$.

\section{Conclusions}

In conclusion, a regime shift of genome size occurred crossing the chasm of eukaryogenesis, and genomic complexification and structuralization (especially chromatin packing) driven by elevated atmospheric oxidation was likely a key macro-evolutionary force for the long-lasting eukaryogenesis that had been collaboratively completed through natural selection by microevolution (e.g., symbiosis and random mutation). Eukaryogenesis paves the way for rapid speciation, leading to adaptive radiation of various life forms on Earth. Further efforts should be made to integrate multidisciplinary evidence to reveal in more detail how processes of different evolutionary levels may have interacted synergistically to complete eukaryogenesis with sequential stepwise hierarchies. 


\section{References}

1. López-García, P. \& Moreira, D. Selective forces for the origin of the eukaryotic nucleus. BioEssays 28, 525-533 (2006).

2. Dacks, J. B. et al. The changing view of eukaryogenesis - fossils, cells, lineages and how they all come together. J. Cell Sci. 129, 3695-3703 (2016).

3. de Roos, A. D. G. The Origin of the Eukaryotic Cell Based on Conservation of Existing Interfaces. Artif. Life 12, 513-523 (2006).

4. Baum, D. A. A comparison of autogenous theories for the origin of eukaryotic cells. Am. J. Bot. 102, 1954-1965 (2015).

5. Lane, N. \& Martin, W. The energetics of genome complexity. Nature 467, 929-934 (2010).

6. Lane, N. Energetics and genetics across the prokaryote-eukaryote divide. Biol. Direct 6, 35 (2011).

7. Koonin, E. V. Energetics and population genetics at the root of eukaryotic cellular and genomic complexity. Proc. Natl. Acad. Sci. U. S. A. 112, 15777-15778 (2015).

8. Gregory, T. R. Macroevolution, hierarchy theory, and the C-value enigma. Paleobiology 30, 179-202 (2004).

9. Livina, V. N., Kwasniok, F. \& Lenton, T. M. Potential analysis reveals changing number of climate states during the last 60 kyr. Clim. Past. 6, 77-82 (2010).

10. Hirota, M., Holmgren, M. \& Van Nes, E. H. Scheffer, M. Global resilience of tropical forest and savanna to critical transitions. Science 334, 232-235 (2011).

11. $\mathrm{Xu}, \mathrm{C}$. et al. Remotely sensed canopy height reveals three pantropical ecosystem states. Ecology 97, 2518-2521 (2016).

12. Mukherjee, S. et al. Genomes Online database (GOLD) v.8: overview and updates. Nucleic Acids Res. 49, D723-D733 (2020).

13. Kullman, B., Tamm, H. \& Kullman, K. Fungal Genome Size Database. http://www.zbi.ee/fungal-genomesize/ (2005).

14. Leitch, I. J., Johnston, E., Pellicer, J., Hidalgo, O. \& Bennett, M. D. Plant DNA C-values Database (Release 7.1). https://cvalues.science.kew.org/ (2019).

15. Gregory, T. R. Animal genome size database. http://www.genomesize.com/ (2021).

16. Dodd, M. S. et al. Evidence for early life in Earth's oldest hydrothermal vent precipitates. Nature 543, 60-64 (2017).

17. Schopf, J. W. Fossil evidence of Archaean life. Philos. Trans. R. Soc. B-Biol. Sci. 361, 869885 (2006).

18. Martin, W. et al. Early Cell Evolution, Eukaryotes, Anoxia, Sulfide, Oxygen, Fungi First (?), and a Tree of Genomes Revisited. IUBMB Life 55, 193-204 (2003).

19. Retallack, G. J. \& Lawson, J. D. Fossil soils as grounds for interpreting the advent of large 
plants and animals on land. Philos. Trans. R. Soc. Lond. Ser. B-Biol. Sci. 309, 105-142 (1985).

20. Valentine, J. W. The Evolution of Multicellular Plants and Animals. Sci. Am. 239, 140-158 (1978).

21. Jain, I. H., Vijayan, V. \& O'Shea, E. K. Spatial ordering of chromosomes enhances the fidelity of chromosome partitioning in cyanobacteria. Proc. Natl. Acad. Sci. U. S. A. 109, 13638-13643 (2012).

22. Schopf, J. W. Microfossils of the Early Archean Apex Chert: New Evidence of the Antiquity of Life. Science 260, 640-646 (1993).

23. Feng, D. F., Cho, G. \& Doolittle, R. F. Determining divergence times with a protein clock: Update and reevaluation. Proc. Natl. Acad. Sci. U. S. A. 94, 13028-13033 (1997).

24. Vellai, T. \& Vida, G. The origin of eukaryotes: the difference between prokaryotic and eukaryotic cells. Proc. R. Soc. Lond. Ser. B-Biol. Sci. 266, 1571-1577 (1999).

25. Liu, Y. et al. Expanded diversity of Asgard archaea and their relationships with eukaryotes. Nature 593, 553-557 (2021).

26. Butterfield, N. J. Bangiomorpha pubescens n. gen., n. sp.: implications for the evolution of sex, multicellularity, and the Mesoproterozoic/Neoproterozoic radiation of eukaryotes. Paleobiology 26, 386-404 (2000).

27. Cheng, S. et al. Genomes of Subaerial Zygnematophyceae Provide Insights into Land Plant Evolution. Cell 179, 1057-1067.e14 (2019).

28. Holland, H. D. Evidence for life on Earth more than 3850 million years ago. Science 275, 38-39 (1997).

29. Lane, N. The Vital Question: Why is Life the Way it is? (Profile Books, London, 2015)

30. Planavsky, N. J. et al. A case for low atmospheric oxygen levels during Earth's middle history. Emerg. Top. Life Sci. 2, 149-159 (2018).

31. Xie, P. Who is the "Matchmaker" between Proteins and Nucleic Acids? Innov. 2, 1-35 (2021).

32. Luijsterburg, M. S., White, M. F., van Driel, R. \& Dame, R. T. The Major Architects of Chromatin: Architectural Proteins in Bacteria, Archaea and Eukaryotes. Crit. Rev. Biochem. Mol. Biol. 43, 393-418 (2008).

33. Dame, R. T., Rashid, F.-Z. M. \& Grainger, D. C. Chromosome organization in bacteria: mechanistic insights into genome structure and function. Nat. Rev. Genet. 21, 227-242 (2020).

34. Hirano, T. Condensin-Based Chromosome Organization from Bacteria to Vertebrates. Cell 164, 847-857 (2016).

35. Guha, A., Sinha, R. K. \& Sinha, S. Average packing ratio as a parameter for analyzing the karyotypes of dioecious cucurbits. Caryologia 57, 117-120 (2004).

36. Poma, A., Venora, G., Miranda, M. \& Pacioni, G. The karyotypes of three Tuber species (Pezizales, Ascomycota). Caryologia 55, 307-313 (2002). 
Acknowledgements We thank Profs. Eugene V. Koonin (National Institutes of Health, USA), Meng Li (Institute for Advanced Study, Shenzhen University, China), Pei-Yun Cong (Institute of Palaeontology, Yunnan University, China) for their valuable comments and Dr. Anne Mette Poulsen (Aarhus University) for linguistic assistance. This research was supported by the Strategic Priority Research Program of the Chinese Academy of Sciences (XDB31000000), the National Natural Science Foundation of China (32061143014), and the Yunnan Provincial Department of Science and Technology (202001BB050078). HJW was supported by the Youth Innovation Association of the Chinese Academy of Sciences as an excellent member (Y201859). EJ was supported by the Tübitak Outstanding Researchers Program, BIDEB 2232 (118C250).

Author contributions HJW and PX designed the research. HJW, XZ, LS, and YiL collected the data and performed the analyses of C-value distributions. CX and LS performed the potential landscape model analysis. HJW, XZ, and YiL prepared the first draft of the manuscript, and PX, CX, YaL and EJ contributed greatly to its improvement.

Competing interests The authors declare no competing interests.

\section{Supplementary Information}

Table S1 A list of the prevalent hypotheses on the origin of nucleus

\begin{tabular}{|l|l|c|}
\hline Name & Connotation & Reference \\
\hline $\begin{array}{l}\text { Viral } \\
\text { Memaryogenesis } \\
\text { Hypothesis }\end{array}$ & $\begin{array}{l}\text { The eukaryotic nucleus evolved from a complex DNA virus. The viral ancestor } \\
\text { of the nucleus is proposed to have been a complex enveloped DNA virus } \\
\text { similar to the present-day poxviridae/ASF viruses, except that its host was an } \\
\text { archaeon. It possessed a large linear chromosome and could enter the archaeal } \\
\text { host cell by membrane fusion. }\end{array}$ & 37 \\
\hline $\begin{array}{l}\text { The Viral } \\
\text { (VE) Hypothesis }\end{array}$ & $\begin{array}{l}\text { The first eukaryotic cell was a multimember consortium consisting of a viral } \\
\text { ancestor of the nucleus, an archaeal ancestor of the eukaryotic cytoplasm, and a } \\
\text { bacterial ancestor of the mitochondria, a cell wall-less archaeon and an } \alpha- \\
\text { proteobacterium established a syntrophic relationship, and then a complex } \\
\text { DNA virus permanently lysogenized the archaeal syntrophy to produce a } \\
\text { consortium of three organisms that evolved into the eukaryotic cell. }\end{array}$ & 38 \\
\hline $\begin{array}{l}\text { Updated Viral } \\
\text { Eukaryogenesis }\end{array}$ & $\begin{array}{l}\text { The eukaryotic nucleus evolved from the viral factory of a DNA virus that } \\
\text { infected the archaeal ancestor of the eukaryotes. }\end{array}$ & 39 \\
\hline $\begin{array}{l}\text { Virus Origin } \\
\text { Symbiotic } \\
\text { Hypothesis }\end{array}$ & $\begin{array}{l}\text { Large DNA viruses, such as poxviruses, led to the emergence of the eukaryotic } \\
\text { cell nucleus. Posing symbiotic contact of an orthopoxvirus ancestor with an } \\
\text { archaebacterium. }\end{array}$ & 41 \\
\hline
\end{tabular}




\begin{tabular}{|c|c|c|}
\hline $\begin{array}{l}\text { Updated Viral } \\
\text { Origin Symbiotic } \\
\text { Hypothesis }\end{array}$ & $\begin{array}{l}\text { An ancestral virus of currently existing giant viruses of PAM (Phycodnaviridae, } \\
\text { Mimiviridae-related viruses, Mimiviridae, Asfarviridae, Pandoraviruses/ } \\
\text { Mollivirus) superclade constructed a VF (viral factory) in the cytoplasm of } \\
\text { proto-eukaryotic cells, which was surrounded by a cytoplasmic inner } \\
\text { membrane (putatively ER). The host cell developed a membrane } \\
\text { compartmentalization to protect genomic DNA from viral attacks. }\end{array}$ & 41 \\
\hline $\begin{array}{l}\text { Endosymbiotic } \\
\text { Models }\end{array}$ & $\begin{array}{l}\text { The nucleus derives from the incorporation of an archaeon within a bacterium. } \\
\text { A eubacterial host that engulfed an archaebacterial endosymbiont that } \\
\text { underwent a transformation into the nucleus } \\
\text { key event in the origin of the eukaryotic cell is postulated to be the engulfment } \\
\text { of an 'eocyte' archaebacterium by a Gram-negative eubacterium that } \\
\text { presumably lacked a cell wail. (b) As the membrane of the host surrounded the } \\
\text { guest species, its own membrane (containing ether-linked lipids) became } \\
\text { redundant and was lost. (c) Eventual separation of the internalized membrane } \\
\text { from the plasma membrane led to the formation of the nuclear envelope and the } \\
\text { endoplasmic reticulum. The formation of these new compartments was pre- } \\
\text { ceded or accompanied by duplication of the genes for the chaperone proteins } \\
\text { (e.g. hsp70, hsp90, etc.). The transfer of the host genome to the newly formed } \\
\text { nucleus, and an assortment of the genes from the two parents, led to the } \\
\text { formation of the ancestral eukaryotic cell. }\end{array}$ & 42 \\
\hline $\begin{array}{l}\text { Chimeric Symbiotic } \\
\text { Models }\end{array}$ & $\begin{array}{l}\text { Archaea and bacteria would be the two only survivor lines descending from the } \\
\text { last common ancestor and eukaryotes would derive from the merging of the } \\
\text { two. The incorporation of the future mitochondrion to an archaeal host } \\
\text { triggered eukaryogenesis. }\end{array}$ & 1 \\
\hline Searcy's Hypothesis & $\begin{array}{l}\text { Sulfur-mediated symbiosis between a wall-less, sulfur-respiring Thermoplasma } \\
\text { - like archaeon and photo- or chemoautotrophic } \mathrm{H}_{2} \mathrm{~S} \text {-utilizing bacterium. }\end{array}$ & 43 \\
\hline $\begin{array}{l}\text { Hydrogen } \\
\text { Hypothesis }\end{array}$ & $\begin{array}{l}\text { A hydrogen-mediated symbiosis between a hydrogenoclastic methanogenic } \\
\text { archaeon and a hydrogen-producing alphaproteoba cterium, with hydrogen } \\
\text { being used to reduce the } \mathrm{CO}_{2} \text { also released by the bacterium for } \\
\text { methanogenesis. }\end{array}$ & 43 \\
\hline $\begin{array}{l}\text { HS Syntrophy } \\
\text { Hypothesis }\end{array}$ & $\begin{array}{l}\text { A complex sulfate-reducing deltaproteobacterium (host). An endosymbiotic } \\
\text { hydrogen-producing Asgard-like archaeon (future nucleus). A metabolically } \\
\text { versatile, facultatively aerobic, sulfide-oxidizing and potentially anoxygenic } \\
\text { photosynthesizing alphaproteobacterium (future mitochondrion). }\end{array}$ & 43 \\
\hline $\begin{array}{l}\text { Entangle-Engulf- } \\
\text { Endogenize (E3) } \\
\text { Model }\end{array}$ & $\begin{array}{l}\text { The host of anaerobic archaea is symbiotic with a kind of sulfate-reducing } \\
\text { bacteria. Symbiotic bacteria are receptors of fatty acids and hydrogen produced } \\
\text { by amino acid metabolism of the host. Subsequently, the host and another } \\
\text { aerobic bacteria symbiosis to form mitochondria, involving three species of } \\
\text { prokaryotes. A dual symbiosis, in microoxic environments, of an Asgard } \\
\text { archaeon that degraded amino acids to short-chain fatty acids and hydrogen } \\
\text { with a sulfate-reducing bacterium (SRB) and an aerobic organotrophic } \\
\text { alphaproteobacterium that scavenged toxic } \mathrm{O}_{2} \text {. As the consortium progresses } \\
\text { towards increasingly oxic zones, the interaction with the alphaproteobacterium } \\
\text { becomes stronger until it is engulfed. The SRB symbiosis is transient and } \\
\text { eventually lost. }\end{array}$ & 44 \\
\hline
\end{tabular}




\begin{tabular}{|c|c|c|}
\hline $\begin{array}{l}\text { Reverse Flow } \\
\text { Model: An Updated } \\
\text { Symbiogenetic } \\
\text { Model }\end{array}$ & $\begin{array}{l}\text { A metabolic syntrophy between anaerobic ancestral Asgard archaea and } \\
\text { facultative anaerobic alphaproteobacteria has provided the selective force for } \\
\text { the establishment of a stable symbiotic interaction that has subsequently led to } \\
\text { the origin of the eukaryotic cell. }\end{array}$ & 45 \\
\hline $\begin{array}{l}\text { Updated hydrogen } \\
\text { hypothesis }\end{array}$ & $\begin{array}{l}\text { Hydrogen could transfer from the bacterial symbiont } \delta \text {-Proteobacterium, which } \\
\text { is a fermentative organoheterotroph to a hydrogen-dependent autotrophic } \\
\text { Asgard archaea (Wukongarchaeota) host. }\end{array}$ & 12 \\
\hline $\begin{array}{l}\text { Syntrophic Chimeric } \\
\text { Fusion Hypothesis }\end{array}$ & $\begin{array}{l}\text { A chimeric cell evolved via symbiogenesis by syntrophic merger between an } \\
\text { archaebacterium and a eubacterium. The archaebacterium, a thermoacidophil, } \\
\text { generated hydrogen sulfide to protect the eubacterium. By eubacterial- } \\
\text { archaebacterial genetic integration, the chimera, an amitochondriate } \\
\text { heterotroph. This "earliest branching protist" that formed by permanent DNA } \\
\text { recombination generated the nucleus as a component of the karyomastigont. }\end{array}$ & 46 \\
\hline $\begin{array}{l}\text { The Symbiosis of } \\
\text { Pyrococcus into } \gamma- \\
\text { Proteobacteria }\end{array}$ & $\begin{array}{l}\text { The nucleus emerged from an archaeal endosymbiont (Pyrococcus -like), which } \\
\text { was engulfed by a } \gamma \text {-proteobacterium. }\end{array}$ & 47 \\
\hline Symbiogenic Theory & $\begin{array}{l}\text { A symbiosis between a spirochaete and an archaebacterium without a cell wall } \\
\text { (most likely Thermoplasma-like in her view), leading to both the eukaryotic } \\
\text { flagellum and the nucleus. }\end{array}$ & 48 \\
\hline $\begin{array}{l}\text { Koonin and Yutin's } \\
\text { Hypothesis }\end{array}$ & $\begin{array}{l}\text { the archaeal ancestor of eukaryotes was a complex form, rooted deeply within } \\
\text { the TACK (Thaumarchaeota, Aigarchaeota, Crenarchaeota, Korarchaeota) } \\
\text { superphylum, that already possessed some quintessential eukaryotic features, in } \\
\text { particular, a cytoskeleton, and perhaps was capable of a primitive form of } \\
\text { phagocytosis that would facilitate the engulfment of potential symbionts }\end{array}$ & 49 \\
\hline $\begin{array}{l}\text { Coevolutionary } \\
\text { Theory }\end{array}$ & $\begin{array}{l}\text { The origin of the nucleus depended on the prior evolution of a primitive } \\
\text { endomembrane system and a primitive mitosis, both brought about by and } \\
\text { associated with the origin of phagocytosis. The concerted origins of the } \\
\text { endomembrane system and cytoskeleton, subsequently recruited to form the } \\
\text { cell nucleus and coevolving mitotic apparatus. }\end{array}$ & 50 \\
\hline $\begin{array}{l}\text { Exocytosis } \\
\text { Hypothesis }\end{array}$ & $\begin{array}{l}\text { The first endomembranes to evolve during eukaryote evolution had secretory, } \\
\text { and not phagocytic, function. Eukaryogenesis was initiated not by } \\
\text { phagocytosis, but by the evolution of secretion by exocytosis, with } \\
\text { phagocytosis arising later. The establishment of a secretory endomembrane } \\
\text { system happened before or in parallel with the evolution of a nucleus. }\end{array}$ & 51 \\
\hline
\end{tabular}




\begin{tabular}{|l|l|l|}
\hline $\begin{array}{l}\text { Cavalier-Smith's } \\
\text { Hypothesis }\end{array}$ & $\begin{array}{l}\text { Both the nucleus and the endoplasmic reticulum come from invagination of the } \\
\text { plasma membrane. Eukaryotic cells evolve directly from bacteria and do not } \\
\text { need endosymbiosis. An autogenous (non-symbiotic) origin of a phagocytosing } \\
\text { amitochondriate eukaryote (an archezoon) via point mutational changes leading } \\
\text { to a host that does not need a mitochondrion at all to enjoy its phagocytotic } \\
\text { lifestyle, but acquires one nonetheless. }\end{array}$ & 52 \\
\hline Autogenous Models & Nucleus and cytoplasm evolved from a single prokaryotic lineage. & 4 \\
\hline $\begin{array}{l}\text { Gould and Dring' s } \\
\text { Hypothesis }\end{array}$ & $\begin{array}{l}\text { Endospore formation of Gram-positive bacteria resulted in the origin of the } \\
\text { nucleus. The protoplast of a single cell divides during endospore formation in } \\
\text { such a manner that the cell engulfs a portion of its own cytoplasm, which then } \\
\text { becomes surrounded by a double membrane resulting in the cell's nucleus. }\end{array}$ & 53 \\
\hline $\begin{array}{l}\text { Exomembrane } \\
\text { Hypothesis }\end{array}$ & $\begin{array}{l}\text { Nucleus originated from a single early cell which then evolved into a second } \\
\text { outer cell membrane. }\end{array}$ & 3 \\
\hline
\end{tabular}

\section{References}

37. Bell, J. L. Viral eukaryogenesis: was the ancestor of the nucleus a complex DNA virus? J. Mol. Evol. 53, 251-256 (2001).

38. Bell, J. L. The viral eukaryogenesis hypothesis: a key role for viruses in the emergence of eukaryotes from a prokaryotic world environment. Ann. N.Y. Acad. Sci. 1178, 91-105 (2009).

39. Bell, J. L. Evidence supporting a viral origin of the eukaryotic nucleus. Virus Res. 289, 198168 (2020).

40. Takemura, M. Poxviruses and the Origin of the Eukaryotic Nucleus. J. Mol. Evol. 52, 419425 (2001).

41. Takemura, M. Medusavirus Ancestor in a Proto-Eukaryotic Cell: Updating the Hypothesis for the Viral Origin of the Nucleus. Front. Microbiol. 11, 571831 (2020).

42. Gupta, S. \& Golding, G. B. The origin of the eukaryotic cell. Trends Biochem.Sci. 21, 166171 (1996).

43. López-García, P. \& Moreira, D. The Syntrophy hypothesis for the origin of eukaryotes revisited. NAT. MICROBIOL 5, 655-667 (2020).

44. Imachi, H. et al. Isolation of an archaeon at the prokaryote-eukaryote interface. Nature $\mathbf{5 7 7}$, 519-525 (2020).

45. Spang, A. et al. Proposal of the reverse flow model for the origin of the eukaryotic cell based on comparative analyses of Asgard archaeal metabolism. NAT. MICROBIOL 4, 1138-1148 (2019). 
46. Margulis, L., Dolan, M. F. \& Guerrero, R. The chimeric eukaryote: Origin of the nucleus from the karyomastigont in amitochondriate protists. Proc. Natl. Acad. Sci. U. S. A. 97, 6954-6959 (2000).

47. Horiike, T., Hamada, K., Miyata, D. \& Shinozawa, T. The Origin of Eukaryotes Is Suggested as the Symbiosis of Pyrococcus into $\gamma$-Proteobacteria by Phylogenetic Tree Based on Gene Content. J. Mol. Evol. 59, 606-619 (2004).

48. Margulis, L., Chapman, M., Guerrero, R. \& Hall, J. The last eukaryotic common ancestor (LECA): acquisition of cytoskeletal motility from aerotolerant spirochetes in the Proterozoic Eon. Proc. Natl. Acad. Sci. U. S. A. 103, 13080-13085 (2006).

49. Koonin, E. V. \& Yutin, N. The Dispersed Archaeal Eukaryome and the Complex Archaeal Ancestor of Eukaryotes. Cold Spring Harbor Perspect. Biol. 6, a016188 (2014).

50. Cavalier-Smith, T. Origin of the cell nucleus, mitosis and sex: roles of intracellular coevolution. Biol. Direct 5, 7 (2010).

51. Jékely, G. Small GTPases and the evolution of the eukaryotic cell. BioEssays 25, 1129-1138 (2003).

52. Cavalier-Smith, T. The origin of eukaryotic and archaebacterial cells. Ann. N.Y. Acad. Sci. 503, 17-54 (1987).

53. Gould, G. W. \& Dring, G. J. On a possible relationship between bacterial endospore formation and the origin of eukaryotic cells. J. Theor. Biol. 81, 47-53 (1979).

Table S2. Basic characteristics of C-values for various biological kingdoms

\begin{tabular}{|c|c|c|c|c|c|c|c|}
\hline & $n$ & Minimum & $1^{\text {st }}$ quartile & Median & Mean & $3^{\text {rd }}$ quartile & Maximum \\
\hline Prokaryotes & 91287 & $7.86 \times 10^{-7}$ & $2.30 \times 10^{-3}$ & $3.80 \times 10^{-3}$ & $3.77 \times 10^{-3}$ & $5.01 \times 10^{-3}$ & $1.65 \times 10^{-2}$ \\
\hline Bacteria & 89273 & $7.86 \times 10^{-7}$ & $2.36 \times 10^{-3}$ & $3.86 \times 10^{-3}$ & $3.81 \times 10^{-3}$ & $5.03 \times 10^{-3}$ & $1.65 \times 10^{-2}$ \\
\hline Archaea & 2014 & $4.52 \times 10^{-6}$ & $8.62 \times 10^{-4}$ & $1.74 \times 10^{-3}$ & $1.93 \times 10^{-3}$ & $2.70 \times 10^{-3}$ & $6.60 \times 10^{-3}$ \\
\hline Eukaryotes & 22424 & $2.00 \times 10^{-3}$ & $5.8 \times 10^{-1}$ & 1.32 & 4.34 & 3.68 & $1.52 \times 10^{2}$ \\
\hline Fungi & 2404 & $2.00 \times 10^{-3}$ & $3.30 \times 10^{-2}$ & $4.20 \times 10^{-2}$ & $8.38 \times 10^{-2}$ & $5.80 \times 10^{-2}$ & 5.93 \\
\hline Plants & 12017 & $1.00 \times 10^{-2}$ & $7.30 \times 10^{-1}$ & 1.70 & 5.40 & 5.90 & $1.52 \times 10^{2}$ \\
\hline Animals & 8003 & $2.00 \times 10^{-2}$ & $8.40 \times 10^{-1}$ & 1.43 & 4.03 & 3.01 & $1.33 \times 10^{2}$ \\
\hline
\end{tabular}

